\title{
The Mediating Effect of Storying on the Relationship Between Psychological Capital and Salesperson Performance: An Abstract
}

\author{
Edward L. Nowlin, David M. Houghton, and Douglas M. Walker
}

\begin{abstract}
Storytelling is the act of tying together actions and consequences into an interesting narrative that drives sales. Storytelling aids in cognitive reasoning and affects how we view ourselves and others in a social exchange (i.e., a sales encounter). However, storytelling must be perceived as authentic if it is to be impactful. One key to creating authentic stories is for the storyteller to have authentic feelings about what is being said and the message being conveyed. Psychological ownership, or the feeling that an object or idea is "MINE!," can positively impact employee attitudes, organizational commitment, job satisfaction, and extra-role behavior. In short, feelings of psychological ownership toward the firm can place the salesperson in a good frame of mind for producing an authentic story. Thus, we propose that feelings of psychological ownership will drive better storytelling on the part of salespeople. Improved storytelling, in turn, will drive better sales performance. We further propose that sales managers can have a positive impact (moderation) on this process through (1) mentoring their salespeople and (2) empowering them with the tools, resources, and autonomy to do the job.
\end{abstract}

References Available Upon Request

\footnotetext{
E.L. Nowlin $(\bowtie) \cdot$ D.M. Walker

Kansas State University, Manhattan, KS, USA

e-mail: elnowlin@ksu.edu; dmwalker@ksu.edu

D.M. Houghton

Southern Illinois University, Carbondale, IL, USA

e-mail: dhoughton909@gmail.com
} 